\title{
Laparoscopic Evaluation of Pelvic Organs In Case of Infertility
}

\author{
MAHERUNNESSA ${ }^{\mathrm{a}}$, CHOWDHURY TA $^{\mathrm{b}}$, JAHAN $\mathrm{S}^{\mathrm{c}}$, BEGUMN $^{\mathrm{d}}$, SULTANA $^{\mathrm{e}}$, RUMMAN U ${ }^{\mathrm{f}}$, RAHMAN $\mathrm{S}^{\mathrm{f}}$
}

\begin{abstract}
:
Objective: Evaluation of pelvic organs by laparoscopy in infertile patient.

Background: Despite of absence of any known risk factor for infertility various studies indicate that there may be abnormalities in pelvic organ in about two-third of the cases, as evidenced by laparoscopic study. Present study was done to have an idea about the problem in a group of patients reporting to specialised centre.
\end{abstract}

Materials and Methods: It was a prospective study which was undertaken in Gynaecology and Obstetric Department at BIRDEM during the period of January 2001 to December 2001.

Results: The study group comprised 100 cases of infertile patients of age between 20 to 40 years. Sixty seven percent patients had primary infertility and $33 \%$ patients had secondary infertility. Size and shape of uterus was normal in $76 \%$ cases and bicornuate uterus was found in $2 \%$ cases.

\section{Introduction}

Infertility is a public health problem both in developed and developing countries affecting 10 to $15 \%$ of couples. ${ }^{1}$ It is defined as the inability of a couple to conceive after one year of unprotected and adequate

a. Dr. Maherunnessa, Registrar, Department of Obstetrics \& Gynaecology, Ibrahim Medical College \& BIRDEM

b. Prof. T. A. Chowdhury,m Professor, Department of Obstetrics \& Gynaecology, Ibrahim Medical College \& BIRDEM

c. Dr. Samsad Jahan, Associate Professor, Department of Obstetrics \& Gynaecology, Ibrahim Medical College \& BIRDEM

d. Dr. Nurunnahar Begum, Assistant Professor, Department of Paediatrics, Sir Salimullah Medical College \& Hospital.

e. Dr. Samina Sultana, Training Coordinator, icddrb, Dhaka

f. Dr. Umme Rumman, Dr. Shahnaz Rahman, Medical Officer, Department of Obstetrics \& Gynaecology, BIRDEM, Dhaka

Address of Correspondence: Dr. Maherunnessa, MBBS, FCPS (Obstetrics \& Gynaecology), Registrar, Department of Obstetrics \& Gynaecology, Ibrahim Medical College \& BIRDEM Hospital, Tele: 01817 049296, Email : mmaherun@gmail.com

Received: 15 November, 2012

Accepted: 09 July, 2013
Right ovary was normal in 51\%patient and left ovary was normal in 53\%. Polycystic changes of right ovary were observed in $23 \%$ and of left ovary in $22 \%$ cases . Right fallopian tube was normal in $71 \%$ and left fallopian tube was normal in $69 \%$ cases. Patency of right fallopian tube was found in $89 \%$ and patency of left fallopian tube was found in $90 \%$. Eleven percent patients were found to have peritubal adhesion on right side and $10 \%$ on left side. Pouch of Douglas was found to be normal in 69\% cases and 9\% cases had adhesion with obliteration.

Conclusion: Laparoscopy is an important tool for diagnosing anatomical and pathological abnormalities of internal genital organs which plays a major role in infertility management. For treating infertility, we should give appropriate importance on laparoscopic evaluation of pelvic organs.

Key Words: Infertility, Laparoscopy, Pelvic organs.

(Birdem Med J 2013; 3(2): 90-93)

sexual intercourse. It can be primary in which case the couple or woman has never conceived before or secondary when there is prior conception irrespective of the outcome. Diagnostic laparoscopy is generally accepted as the most accurate procedure to detect pelvic organ pathologies like tubal pathology, endometriosis, PID and other conditions which can affect fertility. ${ }^{2}$ Less invasive diagnostic tests such as chlamydia antibody testing (CAT), ultrasonography and hysterosalpingography (HSG) are available, but it is still a matter of debate how the value of these tests compares with laparoscopy in the infertility work-up. ${ }^{3}$ Several studies described risk factors for tubal pathology such as previous abdominal surgery and previous pelvic inflammatory disease (PID). ${ }^{7}$ However, up to $68 \%$ of patients without any of these risk factors can still possess abnormalities as shown by laparoscopy. $8,9,10$ Several studies have described the accuracy of HSG with diagnostic laparoscopy (DLS) as gold standard. A meta-analysis of studies comparing chlamydia antibody titres and laparoscopy for tubal patency and peritubal adhesions has shown that the discriminative capacity 
of chlamydia antibody titres in the diagnosis of any tubal pathology is comparable to that of HSG in the diagnosis of tubal occlusion. ${ }^{11}$ Although chlamydia antibody titre can be determined at low cost, it fails to provide information about the severity of tubal pathology, which is of importance to fertility prognosis and subsequently, to infertility treatment. Furthermore, it cannot detect tubal pathology due to other causes or endometriosis.

With this background the present study was undertaken to assess different anatomical and pathological conditions of fallopian tubes and other pelvic organs by laparoscopy in infertile female patients.

\section{Materials and methods}

In this prospective study, the respondents comprised infertile patients who were admitted and treated in the department of Gynecology and Obstetrics in BIRDEM, Dhaka during the period of January 2001 to December 2001. Patients suffering from both primary and secondary infertility were included in this study. Age of the patients who participated in this study was between 20 to 40 years. Semen analysis reports of their husbands' were reviewed.

Before admission, detailed history was taken and clinical examination was done. A set of basic investigations were carried out for fitness of anesthesia before laparoscopy. In suspected cases of thyroid disease serum thyroid stimulating hormone level was performed. To evaluate any follicular phase defect serum follicule stimulating hormone, luteinizing hormone and serum prolactin levels were done. Finally, patients selected for laparoscopy were admitted on 18-21 days of their menstrual cycle.

The information collected from the patients and the findings of laparoscopy were put together in the data sheet which was analyzed manually.

The study protocol was approved by the Ethical Committee of Bangladesh College of Surgeons and Physicians (BCPS) as a requirement of fulfillment of examination of Fellow of College of Physicians and Surgeons (FCPS). Informed consent was taken from the participants before collection of any information.

\section{Results}

The study group comprised 100 cases of infertile patients of which $81 \%$ were having normal regular menstrual cycle. When assessed for infertility, 67\% and $33 \%$ patients were observed with primary and secondary infertility respectively. Patients with secondary infertility reported $9 \%$ stillbirth, $18 \%$ spontaneous abortions, $21.5 \%$ menstrual regulations, $9 \%$ ectopic pregnancy while $42.5 \%$ patients had previous successful pregnancy.

During laparoscopic procedure, normal, bulky and smaller sized uterus were correspondingly observed in $76 \%, 18 \%$ and $2 \%$ cases and uterus could not be visualized due to adhesion in $2 \%$ cases. Bicornuate uterus was found in 2\% cases. Among all the cases, $9 \%$ patients had fibroid uterus. The laparoscopic findings of both ovaries and tubes are shown in tableIand II respectively. Dye test for detecting the patency of fallopian tubes was positive in $89 \%$ on left and $90 \%$ on right side.

\section{Table-I}

Laparoscopic finding of ovaries $(n=100)$

\begin{tabular}{lcccc} 
Finding & \multicolumn{2}{c}{$\begin{array}{c}\text { Right ovary } \\
\text { No of Percentage } \\
\text { cases }\end{array}$} & \multicolumn{2}{c}{$\begin{array}{c}\text { Left ovary } \\
\text { No. of Percentage } \\
\text { of cases }\end{array}$} \\
\hline Normal Ovary & 51 & $51 \%$ & 53 & $53 \%$ \\
Poly cystic ovary & 23 & $23 \%$ & 22 & $22 \%$ \\
Endometriosis & 7 & $7 \%$ & 7 & $7 \%$ \\
Adhesion & 8 & $8 \%$ & 8 & $8 \%$ \\
Simple cyst & 9 & $9 \%$ & 10 & $10 \%$ \\
Could not visualized & 2 & $2 \%$ & 2 & $2 \%$ \\
\hline
\end{tabular}

Table-II

Laparoscopic finding of fallopian tubes $(n=100)$

Finding Right tube $(\mathrm{n}=100)$ Left tube $(\mathrm{n}=100)$

No Percentage No Percentage of cases of cases

\begin{tabular}{lcccc}
\multicolumn{3}{c}{ of cases } & \multicolumn{3}{c}{ of cases } \\
\hline Normal & 71 & $71 \%$ & 69 & $69 \%$ \\
Peritubal adhesion & 11 & $11 \%$ & 10 & $10 \%$ \\
Tubo ovarian mass & 1 & $1 \%$ & 3 & $3 \%$ \\
Hydrosalphinx & 5 & $5 \%$ & 6 & $6 \%$ \\
Kinking & 6 & $6 \%$ & 5 & $5 \%$ \\
Tortuous & 3 & $3 \%$ & 3 & $3 \%$ \\
Not visualized & 3 & $3 \%$ & 4 & $4 \%$ \\
\hline
\end{tabular}


In $79 \%$ cases pelvic organs were normal in appearance, $5 \%$ cases had endometriosis, and $12 \%$ cases showed adhesion of fallopian tubes with the ovary, uterus and intestine and also with bladder. Pelvic organs were congested in 4\% cases. Pouch of Douglas (POD) was normal in $69 \%$ patients. Mild to moderate adhesion at POD was noted in $11 \%$ cases while obliteration of POD due to severe adhesion was seen in $9 \%$ patients. In addition, endometriosis was found in $4 \%$ cases and pelvic collection of fluid was found in $3 \%$ patients.

Regarding complications of laparoscopy, one patient had post-operative abdominal distension. Uterine perforation occurred during tubal patency test in 1 case. Patients with complications were managed appropriately.

\section{Discussion}

Introduction of laparoscopy has tremendously improved the ability to investigate long standing infertility. Uterus, tubes, ovaries can be visualized by laparoscopy directly and full information about concurrent pelvic pathologies can be obtained.

Ovarian pathologies that cause anovulation lead to infertility. In present study, $22 \%$ ovaries were polycystic, smooth pearly white in colour with thick capsule. There were no sign of ovulation. However, a study conducted by Dhaliwal and colleagues in 1987 found polycystic ovary in only $3.5 \%$ cases. ${ }^{12}$ A normal fallopian tube is needed for ovum transport, fertilization and for transport of fertilized ovum to the uterus. Any abnormalities of fallopian tube interfere with fertility. Function of the tube may be impaired due to peritubal adhesion, hydrosalphings, too long or short tube, kinking and increases tortuosity of tubes. In a study conducted in Pakistan by Hamid et al, 1994, tubal block was found $15 \%$ in their cases. ${ }^{13}$ But in present study, bilateral tubal block was found in $9 \%$ cases, only right sided tubal block was found in $10 \%$ and left sided tubal block was found in $11 \%$ cases.

Abnormalities of the uterus may cause infertility. Fibroid uterus, uterine hypoplasia, infantile uterus, tubercular endometrites are important causes of infertility. In this study, fibroid uterus was found in $9 \%$ cases and bicornuate uterus was found in $2 \%$ cases. Normally uterus is freely mobile. Mobility becomes restricted in $24 \%$ cases due to endometriosis, PID, tuberculosis, pelvic operation etc. In the current study, POD was normal in $69 \%$ cases, $11 \%$ cases mild to moderate adhesion and endometriosis was found in $4 \%$ cases and complete obliteration of POD was found in $9 \%$ cases. On the contrary, Hamid et al showed endometriosis in 9\% cases, adhesion in $29 \%$ cases and complete obliteration of POD in $16 \%$ cases. $^{13}$

\section{Conclusion}

Laparoscopy enables proper evaluation of pelvic organs. It is an important tool for diagnosing anatomical and pathological abnormality of internal genital organs in female patients and plays a major role in infertility management plan. Therefore, laparoscopy should be performed in infertile female patient with suspected pelvic organ abnormality. In Bangladesh laparoscopy is available only in few tertiary centers and private clinics. At the same time laparoscopy requires considerable expertise and is an expensive procedure. As a result most people cannot afford it. Laparoscopy should be made available and affordable at a lower cost at different level of health care facilities so that infertile couples can get benefit of it.

\section{References}

1. Templeton A. Infertility-epidemiology, aetiology and effective management: Health Bull (Edinb) 1995; 53 (5) : 294-298.

2. Chang Y. S. Lee, J. Y. Moon, S. Y. Kim J. G Diagnostic Laparoscopy in Gynaecological disorder, Asia Ocenia J. Obs Gynae Col 1982; 13(5): 29-34.

3. Yu SL and Yap C. Investigating the Infertile Couple: Ann Acad Med Singapore 2003; 32( 5): 611-14.

4. Gour A, Zawiejska A and Mettler L. Hysteroscopy - current trends and challenges: J Obstet Gynecol India 2008; 58( 1): $57-62$.

5. Mohapatra P, Swain S and Pati T. Hysteroscopic Tubal Cannulation: Our Experience, J Obstet Gynaecol India 2004; 54 (5): 498-499.

6. Stewart-Smythe GW and van Iddekinge B. Lessons learned from infertility investigations in the public sector: $S A f r$ Med $J$ 2003; 93( 2 ):141-143.

7. Otolorin EO, Ojengbede $\mathrm{O}$ and Falase AO. Laparoscopic evaluation of the tubo-peritoneal factor in infertile Nigerian women: Int J Gynecol Obstet 1987; 25( 10):4752 .

8. Donnez J, Langerock S, Lecart C and Thomas K. Incidence of pathological factors not revealed by hysterosalpingography but disclosed by laparoscopy in 500 infertile women: Eur J Obstet Gynecol Reprod Biol 1982; 13( 63):69-375.

9. Musich JR and Behrman SJ. Infertility laparoscopy in perspective: review of five hundred cases: Am J Obstet Gynecol 1982; 14(33): 293-303. 
10. Corson SL, Cheng A and Gutmann JN. Laparoscopy in the normal infertile patient: a question revisited: Am Assoc Gynecol Laparosc 2000; 7( 63):317-324.

11. Mol BW, Dijkman B, Wertheim P, Lijmer J, van der Veen $\mathrm{F}$ and Bossuyt PM. The accuracy of serum chlamydial antibodies in the diagnosis of tubal pathology: a metaanalysis: Fertil Steril 1997; 67( 6 ):1031-1037.
12. Dhaliwal LK, Khera KR, Gupta I and Gupta AN. Comparison of hysterosalphingo graphy and Laparoscopy in the evaluation of Tubal factor: Asia Ocenia J.Obset Gynaecol 1987; 13( 1 ):65 -67.

13. Hamid R, Khan KS, Mubeen T and Razzak JA. Laparoscopic appraisal of infertility and Pelvic Pain in Pakistani women: a 5 years audit: J Pak Med Assoc 1994; 44( 2 ) $: 40-42$. 